\title{
FUNCTIONAL JAW ORTHOPAEDICS WITH THE TWIN BLOCK APPLIANCE
}

\author{
MJ Trenouth, Consultant Orthodontist \\ Royal Preston Hospital
}

\section{INTRODUCTION}

A standardised technique for the functional treatment of Class II division I malocclusion was described by Trenouth ${ }^{(1)}$. The technique consisted of three phases. First, semi-rapid maxillary expansion and alignment of the upper arch. Second, correction of the Class II relationships using a modification of the twin block functional appliance introduced by $\mathrm{Clark}^{(2,3)}$ but with steeper bite blocks and excluding the extra-oral traction and intermaxillary elastics. Third, retention using an upper removable appliance with a very steep anterior bite plane.

The key design factors are the height and inclination of the bite blocks. Although Clark originally recommended a $45^{\circ}$ incline on the blocks it has been found that a much steeper incline of $70^{\circ}$ is more efficient and anything less than $45^{\circ}$ is largely ineffective.

The extra-oral traction and intermaxillary elastics present in the original Clark appliance are left off so as to minimise the components and maximise patient tolerance. This approach has become commonly adopted. In fact, the twin block appliance has become the most commonly used functional appliance in the UK with the greatest perceived patient compliance as demonstrated by the survey performed by Chadwick, Banks and Wright ${ }^{(4)}$.

The most common way that a twin block appliance is used is in isolation without a pre-functional expansion or postfunctional retention phase. In such an approach it is used to reduce a severe overjet down to a more manageable mild overjet which can then be treated by conventional orthodontics. This usually involves fixed appliances, often combined with premolar extractions.

The range of cases suitable for functional treatment is, however, increased by combining twin block therapy with a pre-functional expansion and post-functional retention phase of treatment. This reduces the need for extractions and often eliminates the need for a post-functional phase of fixed appliance therapy.

It also means that it is easier for the patient to adapt initially to wearing a single upper removable appliance. By the time they have completed the pre-functional phase of treatment they are already practised at wearing a single appliance and will adapt more easily to the increased bulk of a double twin block appliance.

\section{PHASE I: ARCH COORDINATION}

Before starting the functional phase of treatment, the arches ideally need to be coordinated so that the teeth articulate correctly when the jaw relationship is corrected from Class II to Class I (Figure 1). This rarely occurs naturally because in most cases dento-alveolar compensation results in distortion, particularly of the upper arch. In Class II division I the upper arch is narrowed and the incisors proclined producing a V-shaped Gothic arch, which needs to be converted into a U-shaped Roman arch. In Class II division 2 the upper central incisors are, classically, retroclined and the shorter lateral incisors which are out of lower lip control are proclined. Again, ideal arch form and alignment is required prior to functional therapy as with any crowding or malalignment.

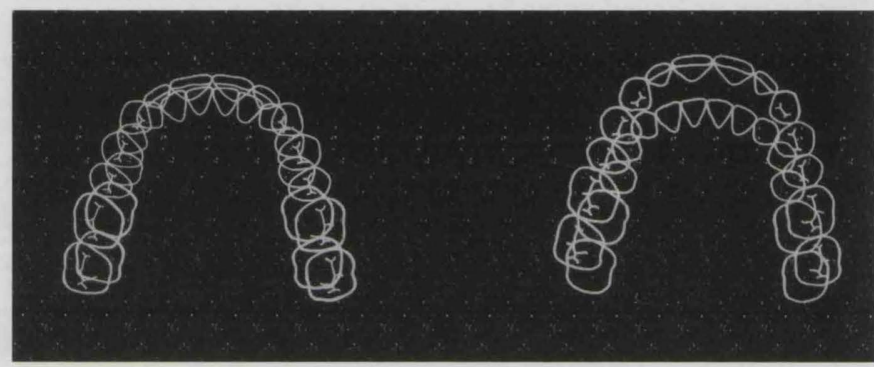

Figure 1 Functional arch correction.

The design of appliance for uncrowded Class II division 1 cases is as follows (Figure 2):

1 double Adams clasps $\underline{65 / 56}$ or $\underline{6 \mathrm{E} / \mathrm{E} 6}(0.7 \mathrm{~mm}$ stainless steel wire)

2 labial bow $\underline{5 / 5}(0.7 \mathrm{~mm})$

3 midline expansion screw

4 flat anterior bite plane

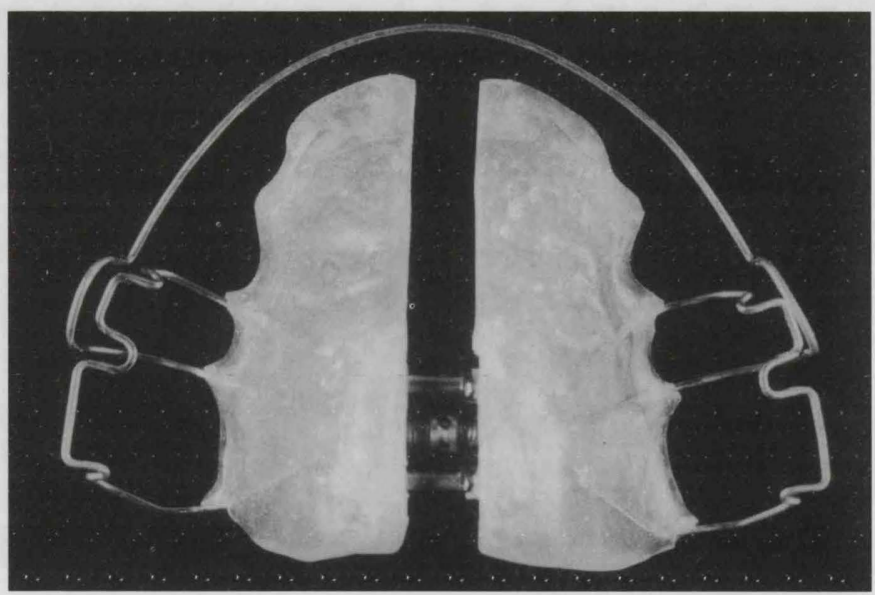

Figure 2 Appliance design Class II division 1

Double clasps are found to be easier to adjust. The labial bow is extended to incorporate the whole arch buccally to maximise control.

In Class II division 2 or malaligned incisor cases, a split palatal bow with loops $(0.8 \mathrm{~mm})$ is added instead of the flat 
anterior bite plane. An upper fixed appliance can also be used in some cases where incisor displacement and malalignment require it.

The screw is turned $1 / 8$ of a full turn per day to achieve semi-rapid maxillary expansion as described by $\mathrm{Mew}^{(5)}$. Activation starts the visit after insertion to allow initial adaptation to the appliance.

Expansion is continued until forward posturing of the mandible to reduce the overjet produces coordinated arches in a Class I relationship.

\section{PHASE 2: FUNCTIONAL CORRECTION}

A modification of the twin block traction appliance is used. The extra-oral traction and intermaxillary elastics originally used by Clark are left out so as to minimise the number of components and improve patient tolerance.

The upper appliance has the following components:

1 double Adams clasps $\underline{65 / 56}$

2 labial bow $\underline{5 / 5}$

3 Southend clasp $\underline{1 / 1}$ to limit incisor retraction when indicated

4 posterior bite blocks with $70^{\circ}$ vertical incline and $5 \mathrm{~mm}$ height

The lower appliance has the following components:

1 Southend clasps $\overline{1 / 1}+\overline{54 / 45}$

2 Anterior bite blocks with $70^{\circ}$ vertical incline and $5 \mathrm{~mm}$ height.

The clasping is arranged to provide maximum anchorage to limit dento-alveolar response and maximise the skeletal correction.

The key design features are the height and inclination of the bite blocks (Fig 3). Although Clark originally recommended a $45^{\circ}$ incline on the bite blocks, a much steeper incline of at least $70^{\circ}$ has been found to be more efficient. Since during the day most of the time is spent with the mandible in its rest position, tooth contact generally occurs only during swallowing, speech and mastication (Table 1). With the blocks at $70^{\circ}$ the mandible is maintained in a forward posture when in the rest position (Fig 4).

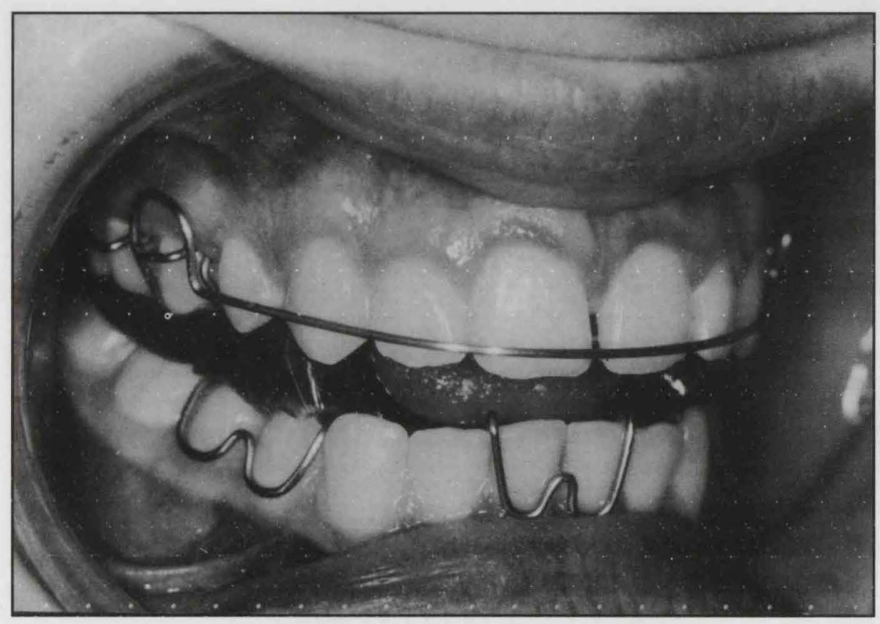

Figure 3 Twin block appliance articulated.

\begin{tabular}{|l|c|c|}
\hline activity & minutes & \% daily time \\
\hline speech & 60 & 4 \\
\hline mastication and swallowing & 100 & 7 \\
\hline swallowing saliva & 12 & 1 \\
\hline rest & 1268 & 88 \\
\hline Total & 1440 & 100 \\
\hline
\end{tabular}

Table 1 Time spent in activities which exert oral pressure

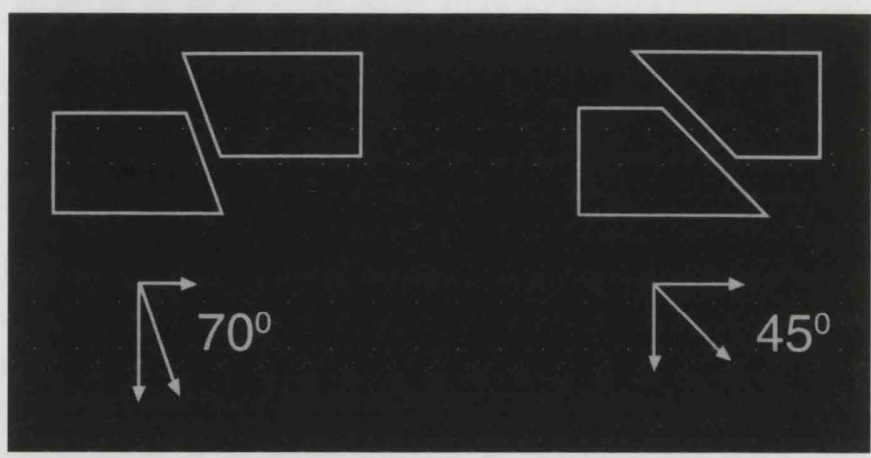

Figure 4 Inclination of the blocks.

The blocks should allow opening along the arc normally made by the hinge axis of the condyles. This is approximately $70^{\circ}$ to the occlusal plane. A $70^{\circ}$ incline on the twin blocks should facilitate constant forward posturing of the mandible, ie when the masticatory system is at rest as well as in function. The twin block is thus more a postural appliance than a functional appliance, depending on the principle that a jaw, which is postured forwards, grows forwards.

Generally, $5 \mathrm{~mm}$ is considered to be the ideal height of the bite blocks. These should be such that a single block does not exceed the freeway space but both blocks occluded together greatly exceed the freeway space. Discomfort is caused when the space is exceeded which, in turn, leads to reflex avoidance with forward posture of the mandible into the most comfortable position.

The rest position of the mandible is subject to servo control by the neuromuscular system. The presence of the bite blocks alters the sensory input to receptors in the masticatory muscles, tendons, periodontal ligament and temporomandibular joint, producing reflex change in the mandibular posture rather than a purely mechanical deflection. The establishment of altered neuromuscular feedback mechanisms appears to be one of the earliest and most rapidly-occurring adaptive mechanisms in the musculoskeletal system since it requires minimal structure change.

The motor program, which guides the mandible from the rest position to maximum intercuspation, requires continuous sensory feedback. Alteration in the occlusion, such as the insertion of a twin block appliance, will result in motor reprogramming and postural adaptation.

The twin block appliance is efficient at distracting the condyle and thus unloading the temporomandibular joint.

The appliance functions by first inducing reflex posturing which, if continuous, results in unloading of the condyle of the temporomandibular joint. This in turn leads to a growth response by proliferation of the condylar cartilage and also bone remodelling of the glenoid fossa. If this growth response is retained for sufficient time, a permanent growth change is produced, involving adaption of muscle attachments, bone remodelling and differential tooth 
eruption. The increased success of twin block appliances over other functional appliances can be explained by their efficiency in posturing the mandible forwards 24 hours a day.

\section{PHASE 3: RETENTION}

Retention is the most important and often the most neglected phase of treatment. It is essential in order to maintain the anteroposterior correction achieved during the functional phase of treatment.

The biodynamic factors responsible for condyle glenoid fossa growth are capable of reversing. Relapse occurs as a result of release of the condyle and ensuing compression against the newly-proliferated retrodiskal tissues.

Once the anteroposterior jaw relationship has been corrected and a normal overjet and overbite established, there is usually a residual posterior open bite. This is especially so in cases where there has been over-eruption of the lower incisors but will also occur due to movement of the condyle down the articular eminence causing disocclusion in the molar region on protrusion.

At this stage a retainer of the following design is used:

1 double Adams clasps $\underline{65 / 56}$

2 labial bow $\underline{5 / 5}$

3 anterior bite plane with a steep vertical slope facing anteriorly at $70^{\circ}$.

\section{ERUPTION}

This standardised technique has been used by the author in its present form for over 15 years. An example of a treated case with before and after treatment records is demonstrated in Figures 5 to 10 .

The technique has recently been evaluated cephalometrically $^{(6)}$. Cephalometric radiographs were taken before and after treatment with the twin block appliance on 30 successfully treated patients with Class II division I malocclusions. A control group was generated from published normative data such that each treated case was matched for sex, age and treatment time.

The cephalometric change during treatment was compared to the natural growth change in the matched control group using a Mann/Whitney U-test (Table 2).

\begin{tabular}{|l|c|c|c|c|c|c|c|}
\hline & $\begin{array}{c}\text { Twin } \\
\text { Block } \\
\text { Group }\end{array}$ & $\begin{array}{c}\text { Control } \\
\text { Group }\end{array}$ & $\begin{array}{c}\text { Mann } \\
\text { Whitney }\end{array}$ & Probability & $\begin{array}{c}\text { Treatment } \\
\text { Effect }\end{array}$ & $\begin{array}{c}2 \times \\
\text { Method } \\
\text { Error }\end{array}$ & $\begin{array}{c}\text { Clinical } \\
\text { Signifi- } \\
\text { cance }\end{array}$ \\
\hline SNA & -0.60 & 0.28 & 3.90 & 0.001 & -0.88 & 0.98 & $\mathbf{x}$ \\
\hline SNB & 2.00 & 0.57 & 5.15 & 0.001 & 1.43 & 0.84 & $\checkmark$ \\
\hline ANB & -2.60 & -0.31 & 5.83 & 0.001 & -2.29 & 1.02 & $\checkmark$ \\
\hline MM & 0.07 & -0.96 & 3.22 & 0.001 & 1.03 & 2.32 & $\mathbf{x}$ \\
\hline UI & -14.37 & 0.06 & 6.21 & 0.001 & -14.31 & 2.46 & $\checkmark$ \\
\hline LI & 1.13 & -0.16 & 0.81 & NS & 1.29 & 2.38 & $\mathbf{x}$ \\
\hline II & 13.47 & 1.05 & 5.12 & 0.001 & 12.42 & 3.90 & $\checkmark$ \\
\hline OJ & -7.20 & -0.24 & 6.65 & 0.001 & -6.96 & 1.02 & $\checkmark$ \\
\hline NSAr & 0.40 & 0.44 & 0.65 & NS & -0.04 & 1.84 & $\mathbf{x}$ \\
\hline SArGo & -0.20 & -0.08 & 0.33 & NS & -0.04 & 1.84 & $\mathbf{x}$ \\
\hline ArGoMe & 0.63 & -0.99 & 2.60 & 0.01 & 1.62 & 3.10 & $\mathbf{x}$ \\
\hline
\end{tabular}

Table 2 Change in cephalometric parameters during treatment

The treatment effect was calculated by subtracting the natural growth change from the treatment change. This was then compared to twice the method error to see if the treatment change was clinically significant.

There was both a statistically and clinically significant reduction in overjet and the upper incisor inclination, and an increase in mandibular length.

\section{REFERENCES}

1 Trenouth MJ. A functional appliance system for the correction of Class II relationships. Br J Orthod 1989;16:169176

2 Clark WJ. The twin block traction technique. Eur J Orthod 1982;4:129-138

3 Clark WJ. The twin block technique: a functional orthopaedic appliance system. Am J Orthod 1988;93:1-18 4 Chadwick SM, Banks P, Wright JL. The use of myofunctional appliances in the UK. A survey of British orthodontists. Dental Update 1998;25:302-308

5 Mew J. Semi-rapid maxillary expansion. Br Dent J 1977;143:301-306

6 Trenouth MJ. Cephalometric evaluation of the twin block appliance in the treatment of Class II division I malocclusion with matched normative data. Am J Orthod Dentofac Orthop 2000;117:54-59 


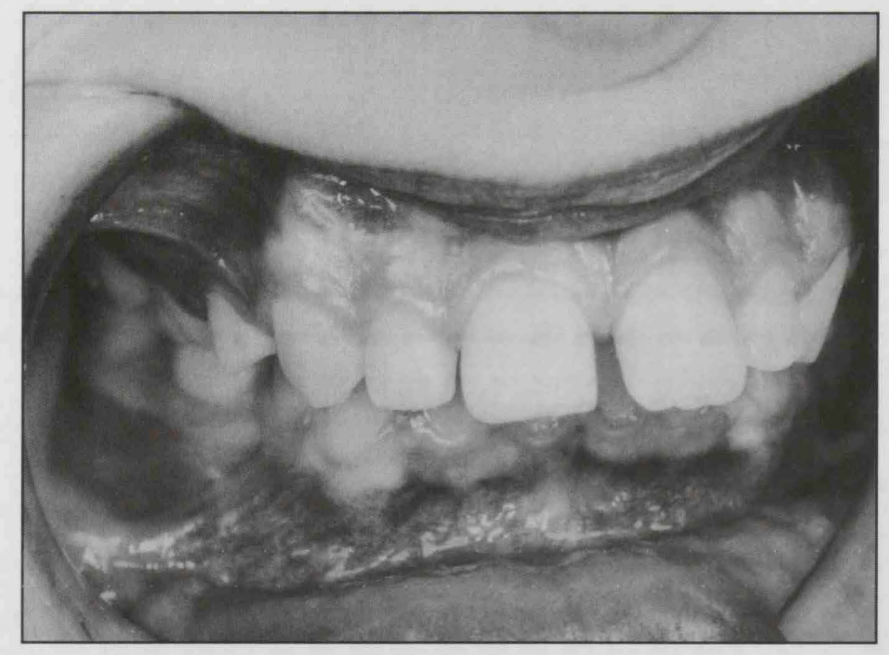

Figure 5 Occlusion before treatment

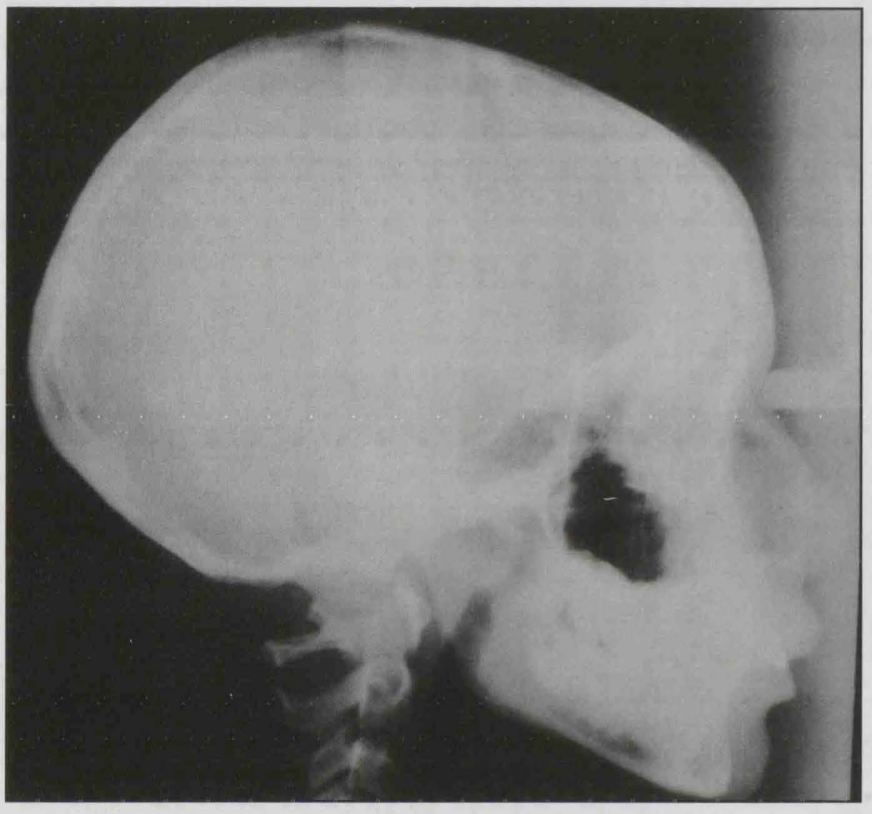

Figure 7 Cephalometric radiograph before treatment

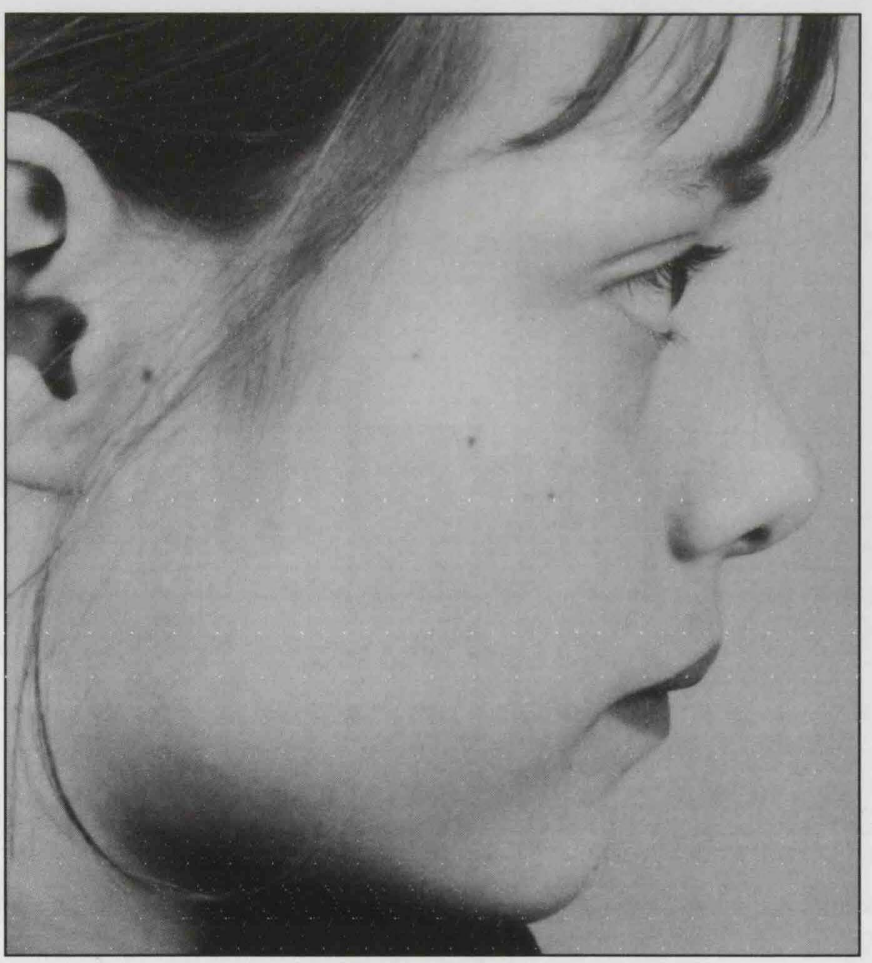

Figure 9 Profile before treatment

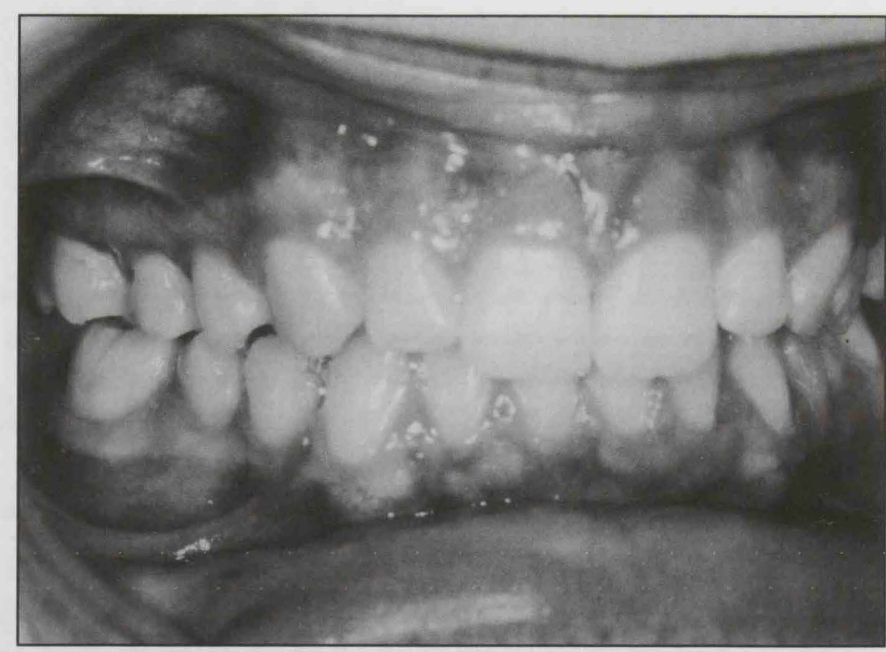

Figure 6 Occlusion after treatment

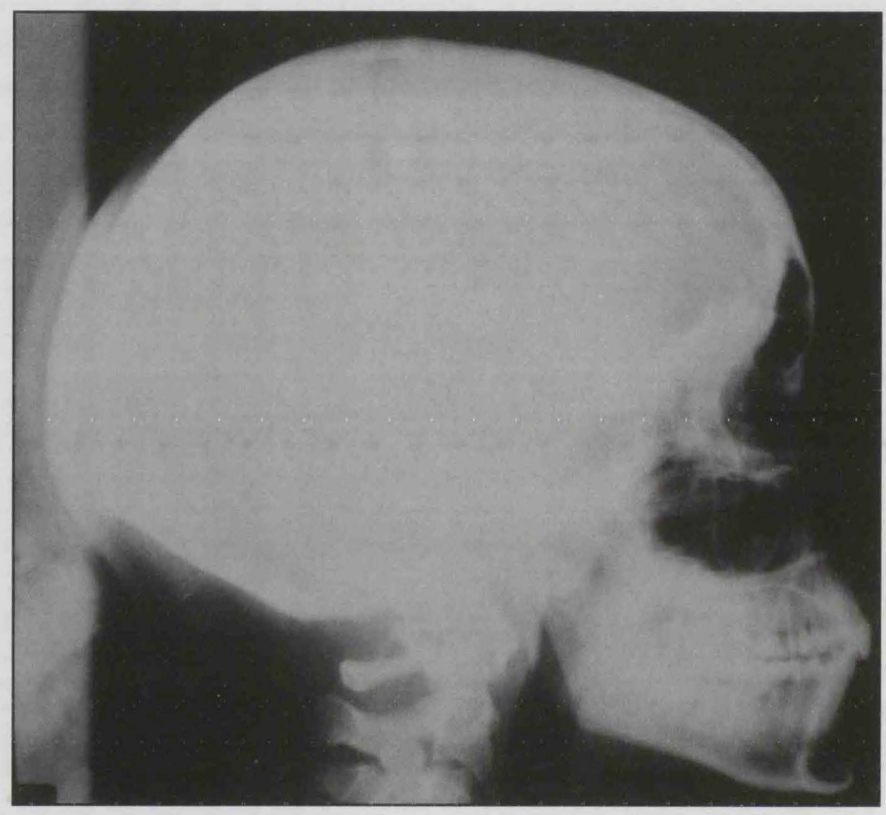

Figure 8 Cephalometric radiograph after treatment

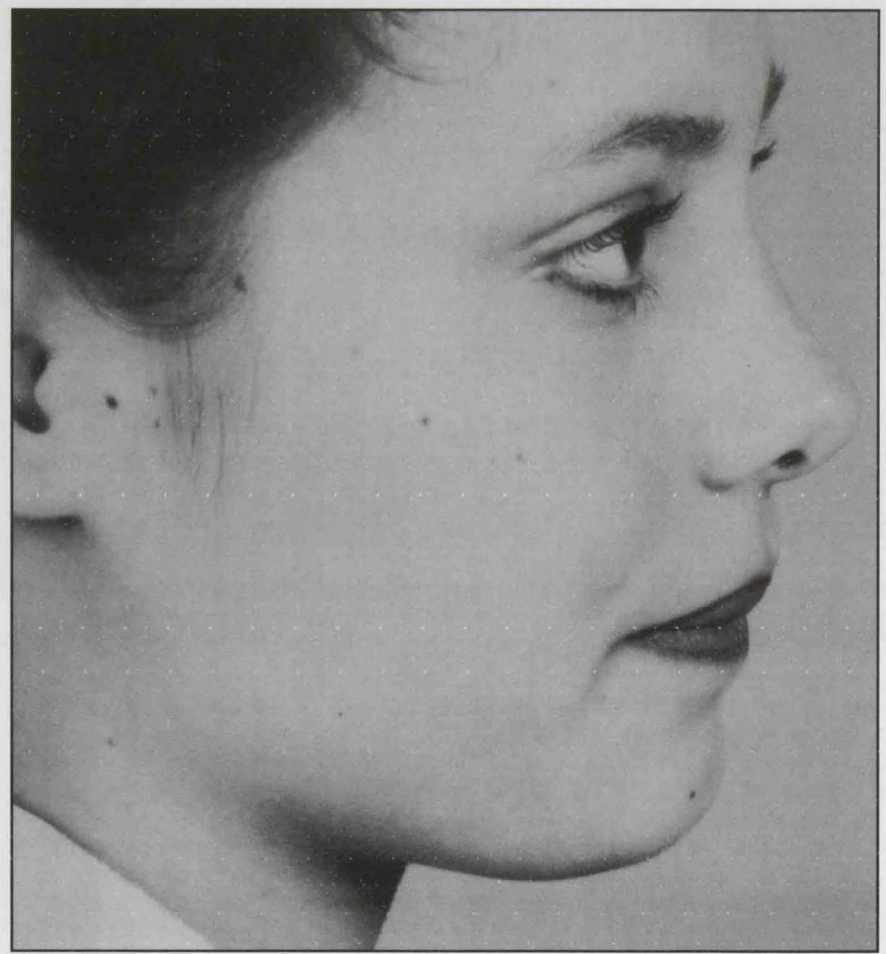

Figure 10 Profile after treatment 